\title{
Determinants of lead exposure in children on the outskirts of Salvador, Brazil
}

\author{
José Antonio Menezes-Filho • Gustavo Freitas de Sousa Viana • \\ Ciro Rodrigues Paes
}

Received: 3 September 2010 / Accepted: 25 May 2011 / Published online: 17 June 2011

(C) The Author(s) 2011. This article is published with open access at Springerlink.com

\begin{abstract}
Lead $(\mathrm{Pb})$ is a toxic heavy metal that is widely distributed throughout the environment. $\mathrm{Pb}$ is an important neurotoxic metal and children are more susceptible to its effect due to their higher absorption rate and greater susceptibility of the developing nervous system. In this work, we evaluated the lead exposure levels in children living near a metallurgical plant and identified risk factors associated with its internal dose. All children, aged 1-10 years and 11 months, living near a metallurgical plant in the great Salvador area, Brazil were evaluated in this cross-sectional study and compared with children from a non exposed area. Occipital hair and blood were used to assess exposure. Air lead levels in the respirable fraction $\left(\mathrm{PM}_{2.5}\right)$ were also measured in both areas. Blood lead levels (BLL), hair lead levels $(\mathrm{PbH})$ and air lead were determined by graphite furnace atomic absorption spectrometry. Spearman correlations analysis was used to evaluate correlations between $\mathrm{BLL}, \mathrm{PbH}$ and descriptors. Significant risk factors
\end{abstract}

J. A. Menezes-Filho - G. F. S. Viana - C. R. Paes Laboratory of Toxicology, College of Pharmacy, Federal University of Bahia, Salvador, Brazil

J. A. Menezes-Filho $(\varangle)$

College of Pharmacy, UFBA, Av. Barão de

Jeremoabo, s/n - Campus Universitário de Ondina, 40170-115 Salvador, Bahia, Brazil

e-mail: antomen@ufba.br were modeled using multivariate linear regression analysis. Air lead levels were approximately tenfolds lower than EPA reference concentration $\left(0.15 \mu \mathrm{g} / \mathrm{m}^{3}\right)$. Median BLL and $\mathrm{PbH}$ were1.65 \pm $1.45 \mu \mathrm{g} / \mathrm{dL}$ and $1.26 \pm 3.70 \mu \mathrm{g} / \mathrm{g}$, respectively, in exposed children. In the referents, medians were BLL $1.20 \pm 1.20 \mu \mathrm{g} / \mathrm{dL} ; \mathrm{PbH} 2.09 \pm 2.06 \mu \mathrm{g} / \mathrm{g}$. No significant difference was observed in biomarkers levels between boys and girls. It was observed a positive weak correlation (Spearman rho $=0.197, p=0.033$ ) between BLL and PbH. Our data show that children's lead body burden measured as BLL or $\mathrm{PbH}$ are low when compared with the recommended reference values. Despite that, we were able to identify four risk factors associated with increased biological lead levels: age, living near industrial site, environmental tobacco smoking and, above all, domestic waste burning. In order to prevent such avoidable exposure, environmental education and proper waste management should be implemented, especially in developing countries.

Keywords Children - Lead body burden • Hair • Blood $\cdot$ Environmental tobacco smoking

\section{Introduction}

Lead $(\mathrm{Pb})$ is a heavy metal abundant on the earth's crust, distributed and found free or 
associated with other elements. In the general population, lead is absorbed by humans through the gastrointestinal tract. In communities near industrial sites and waste incineration facilities, the respiratory route may play an important role. The absorption rate is influenced by particle size (in the case of particulate matter), water solubility, physiological and pathological status of the individual (Strapasson and Job 2006).

Children, especially toddlers, are at greater risk of exposure because they tend to explore the world with their hands and mouth, coming into contact with $\mathrm{Pb}$ present in the soil, house dust and air (Saryan and Zenz 1994). In the gastrointestinal tract, the absorption is more dependent on the nutritional status, specifically on the levels of calcium, iron, phosphorus and protein than on the solubility of $\mathrm{Pb}$ compounds, due to the very low stomach pH (IPCS 1995). Once absorbed, $\mathrm{Pb}$ is distributed in the blood, to the soft tissues (kidney, bone marrow, liver and brain) and in the mineralized tissues: hair, teeth, nails and bones which contain approximately $95 \%$ of the total body burden in adults (ATSDR 2007). Lead easily crosses the blood-brain barrier, but its concentration in the brain is low (WHO 2002). It also crosses the placenta and can transfer $57.4 \%$ of the lead concentration to the fetus (Nashashibi et al. 1999). Lead has direct effect on the developing brain and children's intellectual ability is adversely affected at blood lead concentrations $<10 \mu \mathrm{g} / \mathrm{dL}$ (Bellinger and Needleman 2003; Lidsky and Schneider 2003; Surkan et al. 2007).

The blood lead levels (BLL) as a biomarker is used to establish the degree of lead exposure, as an indicator of recent exposure due to its blood half-life of approximate 35 days (Roberts et al. 2001). However, despite the short half-life, circulating levels of lead may remain high for relatively longer periods as a result of internal remobilization of the metal deposits (Roberts et al. 2001). However, blood sampling is an invasive procedure; on the other hand, hair is a biological matrix easy to collect, to storage and transport (Sanna et al. 2003). Some authors argue that the hair lead levels $(\mathrm{PbH})$ is a good marker of lead body burden in environmental contamination studies, but some aspects related to external contamination and the ability to distinguish between endogenous and external deposition are still a concern (Sanna et al. 2003; Ozden et al. 2007; Stupar et al. 2007). Another aspect is the variation in $\mathrm{Pb}$ concentration in different sub-populations according to age, sex, race (hair colour) and ecological factors which may vary among populations (Barbosa et al. 2006).

Based on the assumption that children living near industrial sites might be more exposed to particulate lead, we aimed to evaluate the possible determinants of exposure to this heavy metal in children living near a ferro-alloy plant. In this study, we evaluated the BLL and $\mathrm{PbH}$ in children living near a ferro-alloy production plant and in children from a reference area. The results were evaluated according to populations' characteristics and habits. The air lead levels in the two populations were also measured and all lead determinations were performed by electrothermal atomic absorption spectrometry.

\section{Material and methods}

Study design and population

This is a cross-sectional study in which we sought to compare all children, aged 1 to $<11$ years, living in the vicinity of a ferro-alloy production plant with children of a reference area in the same age range. The study protocol and consent procedure were approved by the Federal University of Bahia Ethics Committee.

The exposed group resides in the surrounds of the plant, which is located in the metropolitan area of Salvador, capital of the State of Bahia, Brazil (See Fig. 1) in the Cotegipe village (total population 620 inhabitants), a district of Simões Filho with 109,269 inhabitants (IBGE 2007). It is separated from the urban area by the BR324 highway. The geographical coordinates are $12^{\circ} 47^{\prime} \mathrm{S}$ and $38^{\circ} 24^{\prime} \mathrm{W}$. Children living in the community of Capiarara, in the municipality of Lauro de Freitas town, 144,492 habitants (IBGE 2007), and located $7.5 \mathrm{~km}$ southeast from the plant in an upwind direction, were chosen as a reference group. A census of the whole community, performed in March 2008, identified a total of 


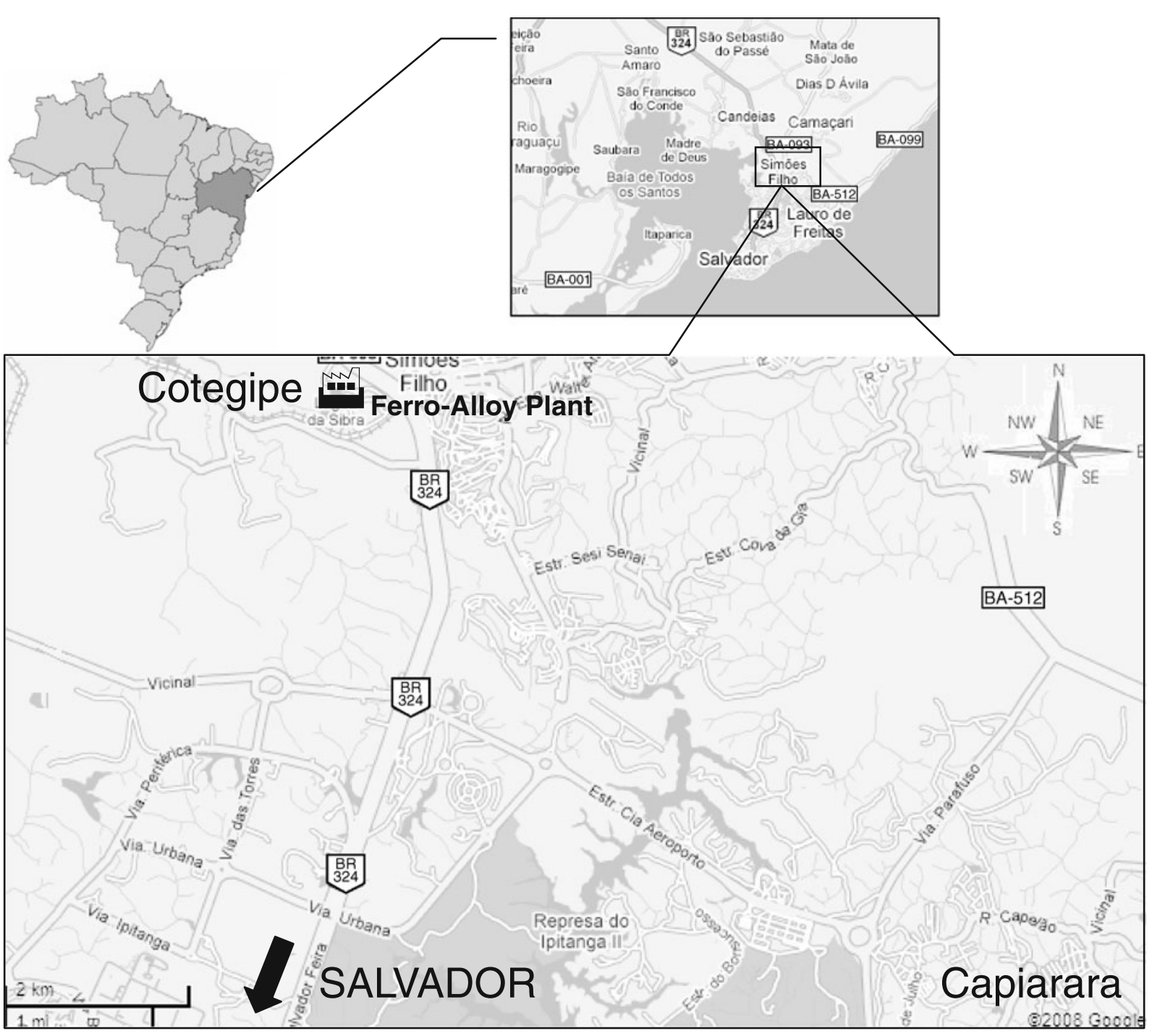

Fig. 1 Map of the study areas, showing the exposed community (Cotegipe) in the vicinity of the ferro-alloy plant and reference area (Capiarara) $7.5 \mathrm{~km}$ upper wind the plant in Great Salvador, Brazil

379 inhabitants $(103$ children in the specified age range).

\section{Recruitment}

In April 2007, a meeting was held with the community living near the plant. The objectives and procedures of the study were explained. Written agreement was obtained from the parents of the 145 children. In July, 2008, a total of 92 (63.5\%) children were present on the sampling day in the local school. Fifteen children refused to have blood sample drawn and four boys had hair too short to provide hair sample.

The study subjects from exposed area provided 77 blood and 88 hair samples. Children in the reference community were recruited following a census. We visited each household and invited the parents or the caregiver (when not a parent) to participate in the study. Parents of 76 children agreed to participate in the study, providing written consent. On the day of biological sampling 48 children $(63.2 \%)$ were available to provide samples. All children agreed to pro- 
vide blood sample and four boys had their hair shaved to the scalp and could not provide samples. Final sample size consisted of 44 children with hair sample. Parents or care-givers responded to a socio-demographic questionnaire, administered by trained interviewers. A questionnaire included information on socio-demographic characteristics of the family: housing structure (roofing type, drinking water access, floor type, distance to main road, etc), parental educational level, time living in the community in years, burning household waste, children general habits (nail biting, exposure to environmental tobacco smoking (ETS), playground area, etc.).

\section{Blood lead levels}

Blood samples were collected by cubital venipuncture into vacuum tubes with $\mathrm{K}_{2}$-EDTA (Vacutainer ${ }^{\circledR}$ BD) and kept under refrigeration until analysis. Sample preparation and analysis were performed according to procedure described by National Institute for Occupational Safety and Health (NIOSH) (1994). In summary, samples were diluted $1+9$ with matrix modifier solution consisting of $1 \%$ Triton $\mathrm{X}-100,0.025 \%$ magnesium nitrate and $0.1 \%$ ammonium phosphate in $0.2 \%$ nitric acid solution (Suprapur ${ }^{\circledR}$, Merck). BLL were analyzed by graphite furnace atomic absorption spectrometry (GFAAS) with Zeeman background correction (SpectraAA 240Z Var$\operatorname{ian}()$. The equipment was daily calibrated with calibration curve in blood prepared with $\mathrm{Pb}$ standard solution (AccuStandard ${ }^{\circledR}$ ) traceable to the National Institute of Standards and Reference Materials (NIST). Quality control sample (Lyphocheck ${ }^{\circledR}$, BioRad) level 1, with target value of $9.2(7.1-11.2 \mu \mathrm{g} / \mathrm{dL})$ was run before and after each batch. The intra-battery precision ranged $2.4 \%$ to $9.4 \%$, and day-to-day precision $9.2 \%$. Accuracy ranged from $83 \%$ to $107 \%$. The detection limit was set at $0.2 \mu \mathrm{g} / \mathrm{dL}$.

Hair lead levels

A tuft of hair of approximate $0.5 \mathrm{~cm}$ diameter was cut off with a surgical Stainless steel scissor as close as possible to the scalp in the occipital region, after tying with a Teflon string at the prox- imal end. For boys with short hair (less than $2 \mathrm{~cm}$ in length), an equivalent amount was trimmed directly into the sterile sampling plastic bag. After identification with the proper child code, the Sampling bags were stored at room temperature until analysis. In the laboratory, hair samples were washed according to the procedure described by Wright et al. (2006). Briefly, the first centimeter or the amount available was washed for $15 \mathrm{~min}$ in $10 \mathrm{~mL}$ of $1 \%$ Triton X-100 solution in a $50-\mathrm{mL}$ beaker in ultrasonic bath. Rinsing was performed several times with Type I pure water (Milli-Q, Millipore $\left.{ }^{\circledR}\right)$. Hair samples were dried wrapped in Whatman $\mathrm{N} \# 1$ filter paper in a drying oven at $70^{\circ} \mathrm{C}$ overnight. Approximately $10 \mathrm{mg}$ of hair was weighed in $50 \mathrm{~mL}$ beaker and mineralized with $2 \mathrm{ml}$ of spectroscopic grade concentrated $\mathrm{HNO}_{3}$ acid for $2 \mathrm{~h}$ on an $80^{\circ} \mathrm{C}$ hotplate. The mineralized was then diluted to $10 \mathrm{~mL}$ with Type I pure water in a polypropylene centrifuge tube (Corning ${ }^{\circledR}$ ). Acid digested samples and reference material were analyzed by GFAAS. All glassware and plasticware were thoroughly decontaminated by soaking for $24 \mathrm{~h}$ in 3\% neutral detergent (Ex$\operatorname{tran} \AA$, Merck), followed by soaking overnight in $10 \% \mathrm{HNO}_{3}$ and finally rinsed with Type I pure water. Reagent blanks were analyzed along with samples in every batch. The detection limit was $0.1 \mu \mathrm{g} / \mathrm{L}$. Routine checks of accuracy and precision were accomplished using human hair reference material from the International Atomic Energy Agency (IAEA-085). The intra-batch and batch-to-batch precisions were $4.4 \%$ and $5.1 \%$, respectively. Accuracy in the concentration range of 8.3 to $9.3 \mu \mathrm{g} / \mathrm{L}$ was $103.2 \%$. All samples and SRM were determined in duplicates and a difference lower than $10 \%$ was considered acceptable. The detection limit was set at $0.1 \mu \mathrm{g} / \mathrm{L}$.

\section{Air lead}

Air $\mathrm{Pb}$ in $\mathrm{PM}_{2.5}$ was measured over a period of 7 days in August 2007 approximately $1.5 \mathrm{Km}$ from the plant and about $50 \mathrm{~m}$ from the school and the day-care. In the reference area, air sampler was set up on the roof of the elementary school, which is located in the centre of the community, and air samples were collected during three 24-h consecutive periods. Sampling was performed 
using a Cyclone URG (URG 2000) coupled to a vacuum pump adjusted to $10 \mathrm{~L} / \mathrm{min}$ flow. The $47 \mathrm{~mm}$ diameter quartz membranes (SKC®) were extracted according to the Environmental Protection Agency (EPA) procedure (Compendium Method IO-2.1 EPA) (2008). Field and reagent blanks along with spiked quartz membranes were analyzed. The accuracy as recovery was calculated at $94 \%$.

\section{Data analysis}

Univariate and bivariate summary statistics and distributional plots were examined for all variables. In order to avoid data loss, the value of the detection limit $(0.2 \mu \mathrm{g} / \mathrm{dL})$ was assigned to samples with BLL below the detection limit (DL). Data normality was examined by the Kolmogorov-Smirnov (K-S) test. Due to the lack of normality in untransformed data, median comparisons between groups were done using non-parametric tests (Mann-Whitney) and proportions were compared using Fisher exact test (Chi-square) additionally $t$ test and ANOVA have been used in the tables. Possible correlations between $\mathrm{BLL}, \mathrm{PbH}$ and descriptors were individually explored using Spearman correlation analysis. All relationships were significant at the 0.05 level. Multiple linear regression (MLR) modeling was applied to identify the factors that could affect lead exposure on the final study subjects who provided blood samples $(n=125)$. Variables were coded 1 for children living near the plant, living with at least one smoker at home and for those who parents reported burning domestic waste, otherwise coded 2. Age was entered in the model in months as a continuous variable. Covariates were included in the model if correlation coefficients were $>0.100$ and $p<0.05$; models were run backwardly. All statistical analyses were performed using SPSS software (release 13.0 for Windows).

\section{Results}

Air lead levels in the breathable fraction of the particulate matter $\left(\mathrm{PM}_{2.5}\right)$ in Cotegipe had an average concentration $0.011 \mu \mathrm{g} / \mathrm{m}^{3}$ ranging from 0.005 to $0.025 \mu \mathrm{g} / \mathrm{m}^{3}$. In the referent community, the air lead concentration averaged 0.007 , ranging 0.003 to $0.012 \mu \mathrm{g} / \mathrm{m}^{3}$. This difference is not statistically significant $(\mathrm{M}-\mathrm{W} p=0.304)$.

The characteristics of the study populations are presented in Table 1. There were equal proportions of boys and girls in both communities, as well as the proportions of families who had the habit of burning domestic waste. A significant difference $(p=0.04)$ was observed in the proportions of children exposed to environmental tobacco smoking, 29.4\% versus $47.9 \%$, in Cotegipe and Capiarara villages, respectively.

The values of BLL and $\mathrm{PbH}$ according to some exposure factors of the two communities are presented in Table 2. The overall $\mathrm{PbH}$ mean was $2.36 \pm 3.023 \mu \mathrm{g} / \mathrm{g}$ and BLL mean was $1.80 \pm$ $1.396 \mu \mathrm{g} / \mathrm{dL}$. BLL among those living near the plant had mean of $1.90 \mu \mathrm{g} / \mathrm{dL}, 55.8 \%$ of the children had $<2.0 \mu \mathrm{g} / \mathrm{dL}$, with maximum value of $6.71 \mu \mathrm{g} / \mathrm{dL}$ and $14.3 \%$ were below the detection limit $(\mathrm{DL}=0.2 \mu \mathrm{g} / \mathrm{dL})$. Among children from the reference community mean was $1.48 \mu \mathrm{g} / \mathrm{dL}$, $60.4 \%$ had BLL levels below $2.0 \mu \mathrm{g} / \mathrm{dL}$, with maximum value of $5.05 \mu \mathrm{g} / \mathrm{dL}$, of which $20.8 \%$ were below the DL. No statistical difference observed between the means. Hair lead levels of children
Table 1 Sociodemographic characteristics of the studied groups

${ }^{\text {a}}$ Fisher exact Chi-square test $\left(\chi^{2}\right)$ or Student $t$ test $n s$ not significant

\begin{tabular}{llll}
\hline & Exposed \% (n) & Referents \% (n) & $p$ Value $^{\mathrm{a}}$ \\
\hline Gender & & & \\
$\quad$ Boys & $51.1(47)$ & $47.9(23)$ & $\mathrm{ns}$ \\
Girls & $48.9(45)$ & $52.1(25)$ & \\
Burning of domestic waste & $55.1(49)$ & $47.7(21)$ & $\mathrm{ns}$ \\
Environmental tobacco smoking & $29.4(25)$ & $47.9(23)$ & 0.04 \\
Nail biting & $33.7(29)$ & $28.3(13)$ & $\mathrm{ns}$ \\
& Mean $\pm \mathrm{SD}$ & Mean $\pm \mathrm{SD}$ & \\
Time living in the area (Years) & $17.47 \pm 12.39$ & $16.64 \pm 12.10$ & $\mathrm{~ns}$ \\
Age (months) & $87.69 \pm 23.18$ & $79.87 \pm 35.53$ & $\mathrm{~ns}$ \\
\hline
\end{tabular}


Table $2 \mathrm{BLL}$ and $\mathrm{PbH}$ according to exposure determinant factors

\begin{tabular}{|c|c|c|c|c|c|c|c|c|c|}
\hline & Exposed & BLL & 77 & 1.90 & 1.65 & 1.45 & 0.20 & 6.71 & BLL \\
\hline & & $\mathrm{PbH}$ & 88 & 2.45 & 1.26 & 3.70 & 0.10 & 24.23 & ns \\
\hline & Referents & BLL & 48 & 1.48 & 1.20 & 1.20 & 0.20 & 5.05 & $\mathrm{PbH}$ \\
\hline & & $\mathrm{PbH}$ & 44 & 2.68 & 2.09 & 2.06 & 0.53 & 10.86 & 0.003 \\
\hline & Burning of $\mathrm{c}$ & mestic & aste & & & & & & \\
\hline & Yes & BLL & 65 & 2.20 & 2.32 & 1.47 & 0.20 & 6.71 & BLL \\
\hline & & $\mathrm{PbH}$ & 70 & 2.39 & 1.73 & 3.13 & 0.10 & 24.23 & $<0.001$ \\
\hline & No & BLL & 55 & 1.24 & 0.91 & 1.09 & 0.20 & 5.05 & $\mathrm{PbH}$ \\
\hline & & $\mathrm{PbH}$ & 56 & 2.76 & 1.63 & 3.51 & 0.10 & 14.06 & ns \\
\hline & ETS & & & & & & & & \\
\hline & Yes & BLL & 47 & 2.15 & 2.14 & 1.41 & 0.20 & 6.71 & BLL \\
\hline & & $\mathrm{PbH}$ & 47 & 3.05 & 2.03 & 3.25 & 0.23 & 14.06 & 0.010 \\
\hline & No & BLL & 75 & 1.49 & 1.04 & 1.31 & 0.20 & 5.53 & $\mathrm{PbH}$ \\
\hline & & $\mathrm{PbH}$ & 79 & 2.08 & 1.49 & 2.94 & 0.10 & 24.23 & 0.024 \\
\hline & Gender & & & & & & & & \\
\hline & Boys & BLL & 61 & 1.68 & 1.50 & 1.35 & 0.20 & 6.71 & BLL \\
\hline a Mann-Whitney & & $\mathrm{PbH}$ & 64 & 2.49 & 1.75 & 2.88 & 0.10 & 14.06 & ns \\
\hline Test $(<0.05)$ & Girls & BLL & 64 & 1.80 & 1.63 & 1.40 & 0.20 & 5.53 & $\mathrm{PbH}$ \\
\hline$n s$ not significant & & $\mathrm{PbH}$ & 68 & 2.57 & 1.62 & 3.57 & 0.15 & 24.23 & ns \\
\hline
\end{tabular}

living near the plant (mean $2.45 \mu \mathrm{g} / \mathrm{g}$ ) were on the majority $(93.2 \%)$ below $10 \mu \mathrm{g} / \mathrm{g}$. Six children had $\mathrm{PbH}$ above this cut-off value. In those living far from the plant mean was $2.68 \mu \mathrm{g} / \mathrm{g}$ only one child had $\mathrm{PbH}$ above this value $(2.3 \%)$. This difference was statistically significant (M-W $p=0.003)$.

Neither BLL nor $\mathrm{PbH}$ values followed a normal distribution pattern $(\mathrm{K}-\mathrm{S} p<0.05)$. A logarithmic transformation was applied in order to obtain a normal distribution for both biomarkers. A weak positive correlation was observed (Spearman rho $=0.197)$ between BLL and $\mathrm{PbH}(p=0.033)$. Other correlation coefficients between covariates are presented in Table 3. It is worthy to emphasize the high statistical significance $(p<0.001)$ of the moderate correlation $(\mathrm{Sp}$ rho $=-0.347)$ between BLL and the child's family habit of burning household waste. There were no significant differences in the medians of BLL and $\mathrm{PbH}$ between boys and girls. It was observed a positive weak correlation between age and BLL (Sp rho = 0.256), no such correlation was detected between child's age and hair lead levels.

Figure 2a shows a graphical representation of the median values of BLL according to environmental tobacco smoking, stratified according to exposure status (exposed or referents). Significant difference $(p<0.001)$ was observed in median

Table 3 Spearman's rank correlation coefficients $(\rho)$ of the main study variables

\begin{tabular}{lllllcccc}
\hline & BLL & $\mathrm{PbH}$ & Residence area & Age (months) & Gender & Burning of waste & ETS & Nail biting \\
\hline BLL & 1 & $0.197^{*}$ & -0.134 & $0.256^{* *}$ & 0.032 & $-0.347^{* *}$ & $-0.241^{* *}$ & -0.030 \\
$\mathrm{PbH}$ & - & 1 & $0.261^{* *}$ & -0.143 & 0.004 & -0.020 & 0.175 & 0.038 \\
Residence Area & - & - & 1 & -0.079 & 0.039 & 0.069 & $-0.210^{*}$ & -0.159 \\
Age (months) & - & - & - & 1 & -0.061 & -0.041 & -0.103 & -0.159 \\
Gender & - & - & - & - & - & -0.022 & -0.009 & -0.099 \\
Burning of waste & - & - & - & - & - & - & -0.034 & 0.093 \\
ETS & - & - & - & - & - & - & 0.117 \\
Nail biting & - & - & - & - & & & - & 1 \\
\hline
\end{tabular}

$* * p<0.01, * p<0.05$ 

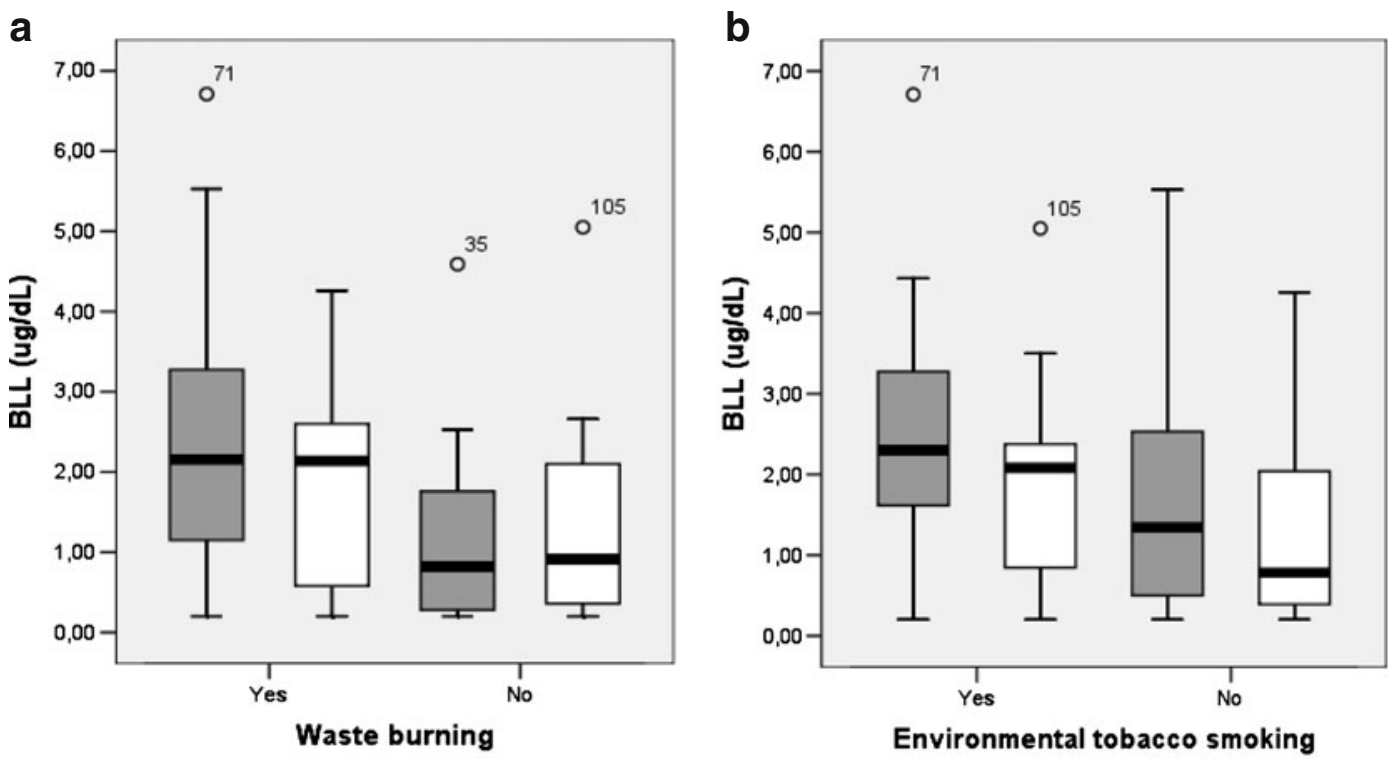

Exposed $\square$ Referents

Fig. 2 BLL according to domestic waste burning (a) and environmental tobacco smoking (b) in children living near the plant (exposed) and in the reference area (referents)

BLL among children living with one or more smokers versus children living in cigarette smoke free environment, 2.15 and $1.53 \mu \mathrm{g} / \mathrm{dL}$, respectively. Figure $2 b$ BLL according to the habit of burning domestic waste; median of 2.32 versus $0.91 \mu \mathrm{g} / \mathrm{dL}(p<0.001)$ among those family who reported to incinerate household waste against those who did not, respectively.

\section{Determinants for lead body burden}

Variables statistically significant $(p<0.05)$ were entered backwardly in the multivariate linear regression (MLR) model, according to its Spearman's correlation coefficient (rho $>0.100$ ). The modeling with $\log \mathrm{PbH}$ identified two factors:

Table 4 Multiple linear regression model for lead in hair

\begin{tabular}{lccc}
\hline Variables & $\begin{array}{l}\text { Regression } \\
\text { coefficients } \beta\end{array}$ & $t$ Statistics & $p$ Value \\
\hline Intercept & 0.254 & -1.149 & 0.253 \\
ETS & -0.220 & -2.420 & 0.017 \\
Residence area & 0.191 & 2.087 & 0.039 \\
\hline
\end{tabular}

$\operatorname{LogPbH}\left(n=117 ; R^{2}=0.122 ; p<0.001\right)$; ANOVA, $F=6.929 ; p=0.002$
ETS and place of residence. Data from the final model are in Table 4. This model explains $12.2 \%$ of the $\mathrm{PbH}$ variance, of which the residence area variable had the greatest contribution $(7.8 \%)$.

The modeling of the determinants of lead internal dose in children using BLL as a biomarker ( $\log$ BLL) identified four major descriptors: area of residence, age (months), ETS and burning of domestic waste. Gender and nail biting did not reach statistical significance to remain in the model. The main parameters of the final model are described in Table 5. This model was highly

Table 5 Multiple linear regression model for blood lead levels

\begin{tabular}{lccc}
\hline Variables & $\begin{array}{l}\text { Regression } \\
\text { coefficients } \beta\end{array}$ & $t$ Statistics & $p$ Value \\
\hline Intercept & 0.687 & 2.352 & 0.021 \\
Residence area & -0.230 & -3.301 & 0.014 \\
Age (months) & 0.054 & 2.750 & 0.007 \\
ETS & -0.197 & -2.161 & 0.033 \\
Domestic waste & -0.293 & -3.301 & 0.001 \\
$\quad$ burning & & & \\
\hline
\end{tabular}

LogBLL $\left(n=117 ; R^{2}=0.249 ; \mathrm{p}<0.001\right) ;$ ANOVA, $F=7.643 ; p<0.001$ 

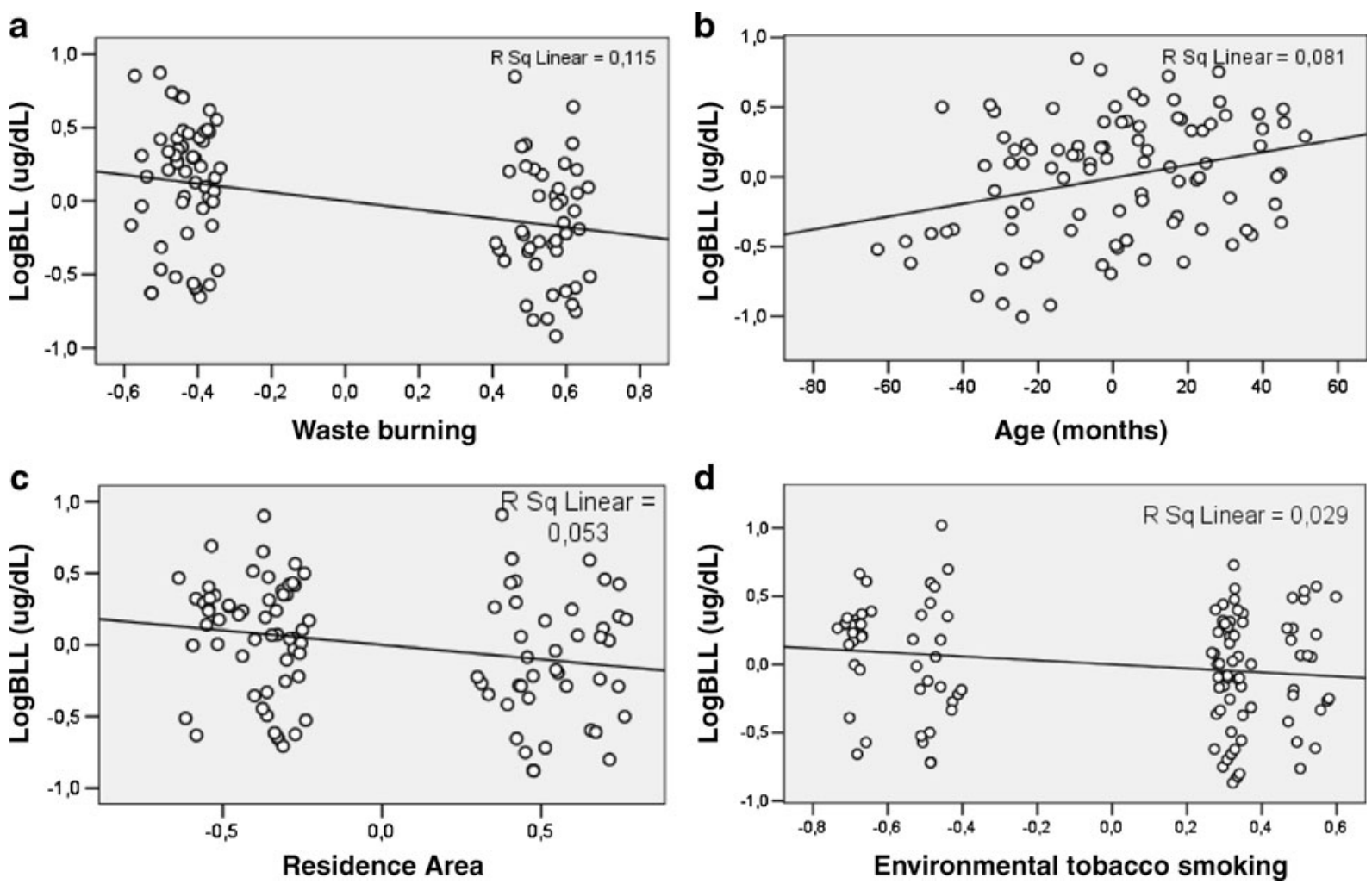

Fig. 3 Scatter plots of predicted BLL by the MLR model according to the determinants: domestic waste burning (a); age (b); area of residence (c) and environmental tobacco smoking (d) arranged in descending order of their partial correlations

significant $(p<0.001)$ and adjusted correlation coefficient of $r^{2}=0.253$. The model shows that factors such as the domestic waste burning contributes with $11.5 \%$ to explain the variance in BLL, child's age with $8.1 \%$; residence area with $5.3 \%$ and ETS with $2.9 \%$. Figure $3 a-d$ present dispersion diagrams of the predicted BLL values, arranged in the order of their partial correlations.

\section{Discussion}

In our study, children's BLL independently of the residence area or their exposure status are in general below one-half the recommended reference value $(<10 \mu \mathrm{g} / \mathrm{dL})$ for children (CDC 1991). However, $44.8 \%$ of children living near the plant and $39.6 \%$ of the children in the reference community had BLL above $2 \mu \mathrm{g} / \mathrm{dL}$, which is the new action level proposed to the CDC by Gilbert and Weiss (2006).
In one study conducted in a day-care on the outskirts of Salvador city, Brazil, children $(n=$ 129) in the age range from 2 to 39 months had mean BLL of $10.7 \pm 7.9 \mu \mathrm{g} / \mathrm{dL}$, of which $33 \%$ exceeded the reference value, in addition to a high prevalence of anaemia and iron deficiency (Carvalho et al. 2000). In Bauru, Brazil, a population survey was performed due to excessive atmospheric lead emissions caused by a battery manufacturer. It included 853 children from 0 to 12 years, in a $1-\mathrm{km}$ radius from the polluting source. Children's BLL in the exposed group (mean $7.72 \mu \mathrm{g} / \mathrm{dL}$ ) were higher than those in the control group, $36.8 \%$ of them had BLL equal or superior to $10 \mu \mathrm{g} / \mathrm{dL}$ (Padula et al. 2006).

We observed that an approximate $7 \%$ prevalence $\mathrm{PbH}$ above the hair reference value $(<10 \mu \mathrm{g} / \mathrm{g})$ (Miekeley et al. 1998) among the exposed children versus $2.3 \%$ among the control group, although median $\mathrm{PbH}$ was higher among these later children. One possible explanation is 
the fact that the community of Capiarara was comprised of unpaved streets, which during dry seasons a great deal of suspended particles of soil are observed. In a heavily industrialized city of Cubatão, Brazil, the mean $\mathrm{PbH}$ concentration in children (aged 1 to 10 years) was $7.25 \pm 8.51 \mu \mathrm{g} / \mathrm{g}$, ranging from 2.5 to $71.4 \mu \mathrm{g} / \mathrm{g}$ (Santos-Filho et al. 1993). Zaida et al. (2007) in an investigation with children from 0 to 12 months from the city of Marrakech, Morocco observed a $\mathrm{PbH}$ average value of $6.6 \mu \mathrm{g} / \mathrm{g}$, which were associated with environmental contamination of soil, water and food. Hair lead levels in children from Istanbul, Turkey, had mean of $2.41 \pm 2.22 \mu \mathrm{g} / \mathrm{g}$, very similar to the mean observed in our study (Sanna et al. 2003). The authors concluded that environmental tobacco smoking and attending school near to main streets were the most important risk factors for high hair lead levels. In our study, ETS was also a significant risk factor for lead exposure, either having $\mathrm{PbH}$ or $\mathrm{BLL}$ as independent variable. We have observed that independently of the residence area, age and burning of household waste, children had higher lead body burden if they lived with one or more smokers.

In our study, gender was not identified as a risk factor for lead exposure. Neither blood lead levels nor lead in hair were significantly different between boys and girls. Sanna et al. (2003) investigated the exposure of 222 children under 5 years old, living on the island of Sardinia, Italy, in regions of Portoscuso and Sestu, and found significant difference between genders. The average values of BLL for boys and girls in the two towns were 11.30 and $3.34 \mu \mathrm{g} / \mathrm{dL}$ vs 4.09 and $3.34 \mu \mathrm{g} / \mathrm{dL}$, respectively. For hair lead levels, they observed the same trend, with the Portoscuso boys having the highest arithmetic mean value (15.51 $\mu \mathrm{g} / \mathrm{g})$, followed by the Portoscuso girls $(8.82 \mu \mathrm{g} / \mathrm{g})$ and then the Sestu boys $(4.03 \mu \mathrm{g} / \mathrm{g})$ and Sestu girls $(2.83 \mu \mathrm{g} / \mathrm{g})$. The authors concluded that the $\mathrm{Pb}$ biomarkers levels reflected the industrial pollution of their cities and suggested that $\mathrm{PbH}$ was a good indicator of exposure. In Cartagena, Colombia, Olivero-Verbel et al. (2007) found no significant difference between boys and girls from 5-9 years, whose mean BLL were $5.91 \pm 0.36$ and $5.03 \pm 0.26 \mu \mathrm{g} / \mathrm{dL}$, respectively. Zaida et al. (2007) detected a significant difference in $\mathrm{PbH}$ in infants according to gender: girls had higher $\mathrm{PbH}(7.3 \pm 4.5 \mu \mathrm{g} / \mathrm{g})$ than boys $(5.9 \pm 3.4 \mu \mathrm{g} / \mathrm{g})$.

Exposure to traffic exhaustion has been demonstrated to be an important risk factor, in Dusseldorf, Germany, $\mathrm{PbH}$ was measured in 245 children age 8-10 years. It was found a mean of $0.87 \mu \mathrm{g} / \mathrm{g}$ (range $0.2-9.9 \mu / \mathrm{g}$ ) for the entire test group, while the hair lead levels in the suburban population were significantly lower than in the two city centre populations (Wilhelm et al. 2002). The authors observed a weak BLL and $\mathrm{PbH}$ correlation $(r=0.217)$ and no correlation at all between $\mathrm{Pb}$ biomarkers and age. In our study, $\mathrm{BLL}$ and $\mathrm{PbH}$ had also a positive weak correlation and BLL was also positively correlated with age. On the other hand, Olivero-Verbel et al. (2007), detected an inverse correlation between BLL and age $(r=-0.191, P=0.009)$. An increase of $\mathrm{PbH}$ with age was observed in infants, which the authors associated to new diet and more mobility of older children (Zaida et al. 2007). We find it more plausible a positive correlation with age because older children tend to play more outdoors, getting in contact with soil particles, and beside that lead is a cumulative toxic heavy metal that may accumulate in bones.

The main determinant factors for $\mathrm{Pb}$ exposure that were identified in this study were the hazardous habit of some families of burning household waste, environmental tobacco smoking, age and place of residence, in descending order. Galazyn-Sidorczuk et al. (2008) evaluated levels of lead in several brands of cigarette, found concentrations of lead ranging from $0.69 \pm$ $0.07 \mu \mathrm{g} /$ cigarette and set the amount of $\mathrm{Pb}$ inhaled could reach 0.208 to $1.033 \mu \mathrm{g}$. Schroijen et al. (2008) in studies of exposure to pollutants with adolescents living in areas around waste incinerators, showed increased body burden of several environmental contaminants, among them $\mathrm{Pb}$, corroborating the findings of this study that the exposure to smoke from the burning of household waste is an important factor for the exposure of children to the metal, besides the possibility of exposure to other contaminants present in the smoke generated during this waste disposal habit. Our data show that burning domestic waste can increase BLL by $2 \mu \mathrm{g} / \mathrm{dL}$, after adjusting for age, 
living in industrial area and environmental tobacco smoking.

Our study had some limitations such as the difference in time between air sampling and rain regime, in both regions. Despite this difference, we observed higher concentration of metals in suspended particulate matter $\left(\mathrm{PM}_{2.5}\right)$ in Cotegipe when the air was supposed to be cleaner due to the rain precipitation. Also, the exposure to passive smoking or ETS could be better informed if we had collected more precise information about the smoking habit at home, as the amount of cigarettes/day smoked by parents and time spent in the presence of their children.

Lead has no physiologic role and is toxic at very low level as has been demonstrated by a recent cohort study (Jusko et al. 2008) that children's intellectual functioning at 6 years of age is impaired by blood lead concentrations well below $10 \mu \mathrm{g} / \mathrm{dL}$. The economical implication of elevated BLL has been thoroughly reviewed by Gilbert and Weiss (2006), who described that in the U.S. the direct and indirect costs to society of elevated BLL were estimated to be $\$ 43.4$ billion. The calculation was based on an average BLL of $2.7 \mu \mathrm{g} / \mathrm{dL}$ for a cohort of children at 5 years of age, a loss of 0.25 IQ point for each $1 \mu \mathrm{g} / \mathrm{dL}$ of blood lead increment on a lifetime basis.

\section{Conclusions}

The data of this study demonstrated that independently of the environmental tobacco smoke status, domestic waste burning and age a child who moved from the reference area to the exposed area would have an increase in almost $1.7 \mu \mathrm{g} / \mathrm{dL}$ in their BLL. However, in our study, low levels were observed in comparison with the current reference values for children established by CDC. Burning of domestic waste and environmental tobacco smoking were also factors that contributed significantly to its internal dose.

Simple measures should be implemented in order to prevent such exposures, especially in developing countries: environmental education; domestic waste should be properly collected and disposed of in adequate landfills; domestic and industrial waste should be banned; anti-smoke campaigns should emphasize the risks of environmental tobacco smoking and address the issue of children exposure at home or in public places. Mothers should take particular caution, avoiding smoking during the gestational and lactation periods.

Acknowledgements The authors would like to express their gratitude to the Cotegipe and Capiarara Village communities, especially to the children and their parents, who kindly collaborated to the study. Menezes-Filho, JA is an Irving J. Selikoff International Scholar of the Mount Sinai School of Medicine, USA. This work was supported in part by grant award number D43TW00640 from the Fogarty International Center. The content is solely the responsibility of the authors and does not necessarily represent the official views of the Fogarty International Center or the National Institutes of Health.

Open Access This article is distributed under the terms of the Creative Commons Attribution Noncommercial License which permits any noncommercial use, distribution, and reproduction in any medium, provided the original author(s) and source are credited.

\section{References}

Agency for Toxic Substances and Disease Registry (ATSDR) (2007). Toxicological profile for lead. Atlanta: Department of Health and Human Services, Public Health Services.

Barbosa, J. F., Tanus-Santos, J. E., Gerlach, R. F., \& Parsons, P. J. (2006). A critical review of biomarkers used for monitoring human exposure to lead: Advantages, limitations and future needs. Ciênca Saúde Coletiva, 11, 229-241.

Bellinger, D. C., \& Needleman, H. L. (2003). Intellectual impairment and blood lead levels. The New England Journal of Medicine, 349, 500-502.

Carvalho, F. M., Aguiar, A. S., Vieira, L. A., Gonçalves, H. R., Costa, A. C. A., \& Tavares, T. M. (2000). Anemia, deficiência de ferro e intoxicação pelo $\mathrm{Pb}$ em crianças de uma creche de Salvador. Bahia. Rev. Baiana Saude Publica., 24, 32-41.

Centers for Disease Control and Prevention (CDC) (1991). Preventing lead poisoning in young children. Atlanta: CDC.

Environmental Protection Agency (EPA) (2008). Lead air quality standards. Available in http://www.epa. gov/air/lead/standards.html. Accessed 26 Dec 2008.

Galazyn-Sidorczuk, M., Brzóska, M. M., \& MoniuszkoJakoniuk, J. (2008). Estimation of Polish cigarettes contamination with cadmium and lead, and exposure to these metals via smoking. Environmental Monitoring and Assessment, 137, 481-493. 
Gilbert, S. G., \& Weiss, B. (2006). A rationale for lowering the blood lead action level from 10 to $2 \mu \mathrm{g} / \mathrm{dL}$. Neurotox, 27, 693-701.

Instituto Brasileiro de Geografia e Estatística (IBGE) (2007). Censo demográfico de 2007. Available in http://www.ibge.gov.br/cidadesat/topwindow.htm?1. Accessed 26 Oct 2007.

International Program on Chemical Safety (IPCS) (1995). Environmental health criteria 165: Inorganic lead. Geneva: WHO.

Jusko, T. A., Henderson, C. R., Lanphear, B. P., CorySlechta, D. A., Parsons, P. J., \& Canfield, R. L. (2008). Blood lead concentrations $<10 \mu \mathrm{g} / \mathrm{dL}$ and child intelligence at 6 years of age. Environmental Health Perspectives, 116, 243-248.

Lidsky, T. I., \& Schneider, J. S. (2003). Lead neurotoxicity in children: Basic mechanisms and clinical correlates. Brain, 126, 5-19.

Miekeley, N., Dias Carneiro, M. T., \& da Silveira, C. L. (1998). How reliable are human hair reference intervals for trace elements? The Science of the Total Environment, 218, 9-17.

Nashashibi, N., Cardamakis, E., Bolbos, G., \& Tzingounis, V. (1999). Investigation of kinetic of lead during pregnancy and lactation. Gynecologic and Obstetric Investigation, 48, 158-62.

National Institute for Occupational Safety and Health (NIOSH) (1994). NIOSH manual of analytical methods: Lead in blood and urine (Method 8003). 4, 94113.

Olivero-Verbel, J., Duarte, D., Echenique, M., Guette, J., Johnson-Restrepo, B., \& Parsons, P. J. (2007). Blood lead levels in children aged 5-9 years living in Cartagena. Colombia Science Total Environment, 372, 707-716.

Ozden, T. A., Gökçay, G., Ertem, H. V., Süoğlu, O. D., Kiliç, A., Sökücü, S., et al. (2007). Elevated hair levels of cadmium and lead in school children exposed to smoking and in highways near schools. Clinical Biochemistry, 40, 52-56.

Padula, N. A. M. R., Abreu, M. H., Miyazaki, L. C. Y., \& Tomita, N. E. (2006). Lead poisoning and child health: Integrated efforts to combat this problem. Cadernos Saude Pubica, 22, 163-171.

Roberts, J. R., Reigart, J. R., Ebeling, M., \& Hulsey, T. C. (2001). Time required for blood lead levels to decline in nonchelated children. Journal of Toxicology, Clinical Toxicology, 39, 153-160.
Sanna, E., Liguori, A., Palmas, L., Soro, M. R., \& Floris, G. (2003). Blood and hair lead levels in boys and girls living in two Sardinian towns at different risks of lead pollution. Ecotoxicology and Environmental Safety, 55, 293-299.

Santos-Filho, E., Silva, S. E. R., Sakuma, A. M., \& Scorsafava, M. A. (1993). Teores de Pb e mercúrio em cabelo de crianças residentes em Cubatão, na região sudeste do Brasil. Revista de Saude Publica, 27, 81-86.

Saryan, L. A., \& Zenz, C. (1994). Lead and its compounds. In C. Zenz, O. B. Dickerson, \& E. P. Horvath (Eds.), Occupational medicine (pp. 506-541). St. Louis: Mosby-Year Book.

Schroijen, C., Baeyens, W., Schoeters, G., Den Hond, E., Koppen, G., Bruckers, L., et al. (2008). Internal exposure to pollutants measured in blood and urine of Flemish adolescents in function of area of residence. Chemosphere, 71, 1317-1325.

Strapasson, A. B., \& Job, L. C. M. A. (2006). Etanol, meio ambiente e tecnologia Reflexões sobre a experiência brasileira. Rev. Poli. Agric., 15, 51-63.

Stupar, J., Dolinsek, F., \& Erzen, I. (2007). Hair-Pb longitudinal profiles and blood-Pb in the population of young Slovenian males. Ecotoxicology and Environmental Safety, 68, 134-143.

Surkan, P. J., Zhang, A., Trachtenberg, F., Daniel, D. B., McKinlay, S., \& Bellinger, D. C. (2007). Neuropsychological function in children with blood lead levels $<10 \mu \mathrm{g} / \mathrm{dL}$. Neurotox., 28, 1170-1177.

Wilhelm, M., Pesch, A., Rostek, U., Begerow, J., Schmitz, N., Idel, H., et al. (2002). Concentrations of lead in blood, hair and saliva of German children living in three different areas of traffic density. The Science of the Total Environment, 297, 109-118.

World Health Organization (WHO) (2002). Bulletin of the World Health Organization 2002: Lead, unsafe at any level. Geneva: WHO.

Wright, R. O., Amarasiriwardena, C., Woolf, A. D., Jim, R., \& Bellinger, D. C. (2006). Neuropsychological correlates of hair arsenic, manganese, and cadmium levels in school-age children residing near a hazardous waste site. Neurotox., 27, 210-216.

Zaida, F., Chadrame, S., Sedki, A., Lekouch, N., Bureau, F., Arhan, P., et al. (2007). Lead and aluminium levels in infants' hair, diet, and the local environment in the Moroccan city of Marrakech. The Science of the Total Environment, 377, 152-158. 